\title{
INVITED PAPER Transmission Loss of Optical Fibers; Achievements in Half a Century
}

\author{
Hiroo KANAMORI ${ }^{\dagger a)}$, Member
}

\begin{abstract}
SUMMARY This paper reviews the evolutionary process that reduced the transmission loss of silica optical fibers from the report of $20 \mathrm{~dB} / \mathrm{km}$ by Corning in 1970 to the current record-low loss. At an early stage, the main effort was to remove impurities especially hydroxy groups for fibers with $\mathrm{GeO}_{2}-\mathrm{SiO}_{2}$ core, resulting in the loss of $0.20 \mathrm{~dB} / \mathrm{km}$ in 1980 . In order to suppress Rayleigh scattering due to composition fluctuation, pure-silicacore fibers were developed, and the loss of $0.154 \mathrm{~dB} / \mathrm{km}$ was achieved in 1986. As the residual main factor of the loss, Rayleigh scattering due to density fluctuation was actively investigated by utilizing IR and Raman spectroscopy in the 1990s and early 2000s. Now, ultra-low-loss fibers with the loss of $0.150 \mathrm{~dB} / \mathrm{km}$ are commercially available in trans-oceanic submarine cable systems.

key words: optical fiber, transmission loss, Rayleigh scattering, fictive temperature, ultra-low-loss
\end{abstract}

\section{Introduction}

In 1970, Kapron et al. of Corning Glass Works (present Corning) in the US reported on their prototype silica glass optical fiber with a transmission loss of $20 \mathrm{~dB} / \mathrm{km}$ [1]. The value of $20 \mathrm{~dB} / \mathrm{km}$ was a symbolic performance for optical fibers to be comparable to coaxial cables in terms of the repeater distance. Since this achievement, the development of optical fiber quickly gained momentum in the US, the UK, and Japan. Along with the "semiconductor laser that continuously oscillates at room temperature [2]," which was also realized in 1970, "20 dB/km optical fiber" became a milestone in the practical application of optical fiber communication. At half a century from 1970, this paper looks back chronologically over the progress on the transmission loss, which is an attribute that most directly shows the performance of an optical fiber.

\section{Early Days of Optical Fiber}

In advance of 1970, Kao of Standard Telecommunication Laboratories in the UK foretold that the loss of transition metal-free high-purity glass fiber could be below $20 \mathrm{~dB} / \mathrm{km}$ in 1966 [3]. For this achievement, the 2009 Nobel Prize in physics was awarded to him. Meanwhile, in 1964, Nishizawa and Sasaki applied a patent for a graded index (GI) fiber concept. Although this patent application was not successful, researchers said that their prescience regarding

\footnotetext{
Manuscript received August 28, 2020.

Manuscript revised December 8, 2020.

Manuscript publicized February 15, 2021.

†The author is with Optical Communications Laboratory, Sumitomo Electric Industries, Ltd., Yokohama-shi, 244-8588 Japan.

a) E-mail: kanamori-hiroo@sei.co.jp

DOI: $10.1587 /$ transcom.2020EBI0002
}

the potential of optical fiber communication is comparable to Kao's achievements. In 1969, GI fiber made of multicomponent glass was successfully manufactured by Uchida et al. by the ion exchange method [4]. This fiber was named

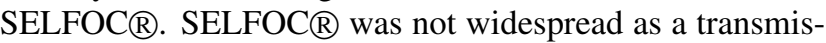
sion line for optical communication because the intrinsic loss of multi-component glass fibers did not reach that of silica fibers which became popular later. The technology of SELFOC®, however, has been widely used as collimating lenses for optical devices as well as copy machines.

\section{Initiatives of Silica Optical Fiber}

The optical fiber reported by Kapron et al. in 1970 was a single-mode (SM) fiber with a core diameter of 3-4 $\mu \mathrm{m}$ and a core/cladding diameter ratio of 1:60, and a loss of 20 $\mathrm{dB} / \mathrm{km}$ was confirmed at a wavelength of $0.6328 \mu \mathrm{m}$. According to a later publication [5], the fiber that achieved $20 \mathrm{~dB} / \mathrm{km}$ was drawn from a silica glass tube, in which silica glass was deposited as a core by using a flame hydrolysis reaction on the inner surface of the tube. The deposited silica glass was doped with $\mathrm{TiO}_{2}$ to increase the refractive index. Immediately after drawing, the fiber showed a large absorption loss due to $\mathrm{Ti}^{3+}$, the reduced state of $\mathrm{Ti}$ ion. By heating the drawn fiber in an oxygen atmosphere to oxidize $\mathrm{Ti}^{3+}$ to the $\mathrm{Ti}^{4+}$ state, the loss of $20 \mathrm{~dB} / \mathrm{km}$ was obtained. Since heating drawn fiber at a high temperature made it brittle, it could not be put to practical use. As a countermeasure, $\mathrm{GeO}_{2}$ has come to be used [6] as a core dopant instead of $\mathrm{TiO}_{2} \cdot \mathrm{GeO}_{2}$ doped fiber does not require heat treatment after drawing because tetravalent state of Ge ion is present stably in silica glass.

Following " $20 \mathrm{~dB} / \mathrm{km}$," Keck et al. of Corning reported that the loss of $7 \mathrm{~dB} / \mathrm{km}$ at $1.06 \mu \mathrm{m}$ in 1972 [7], and $4 \mathrm{~dB} / \mathrm{km}$ at $0.8-0.85 \mu \mathrm{m}$ and $1.05 \mu \mathrm{m}$ in 1973 [8] with multi-mode (MM) fibers. Although the materials and manufacturing methods were not disclosed in the papers at that time, the outside vapor deposition (OVD) method, shown in Fig. 1(a), was developed by Corning [9], [10] around that time. In the OVD method, glass particles called "soot" are generated by a flame hydrolysis reaction of gaseous raw material of glass such as $\mathrm{SiCl}_{4}$ fed to a burner. The soot deposits on the starting mandrel to form a porous preform. Next, the mandrel is removed from the porous preform, and the porous preform is heated at a high temperature to make it transparent, which is called "sintering" process.

In 1974, MacChesney et al. of Bell Laboratories in 


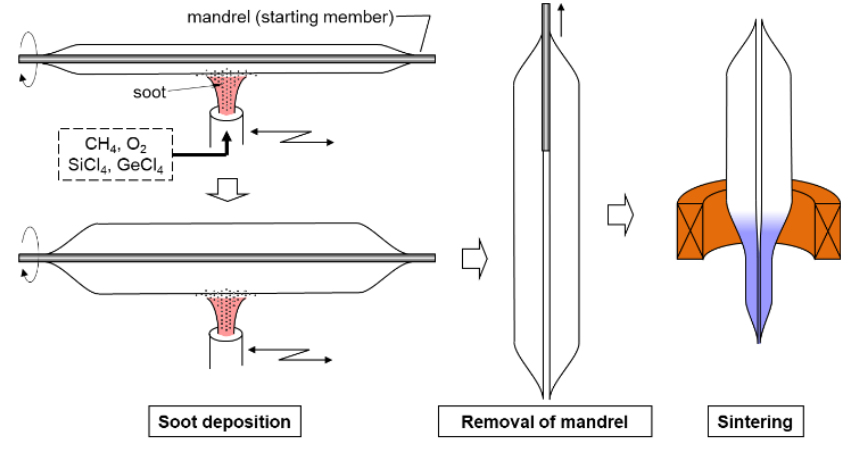

(a) The OVD method

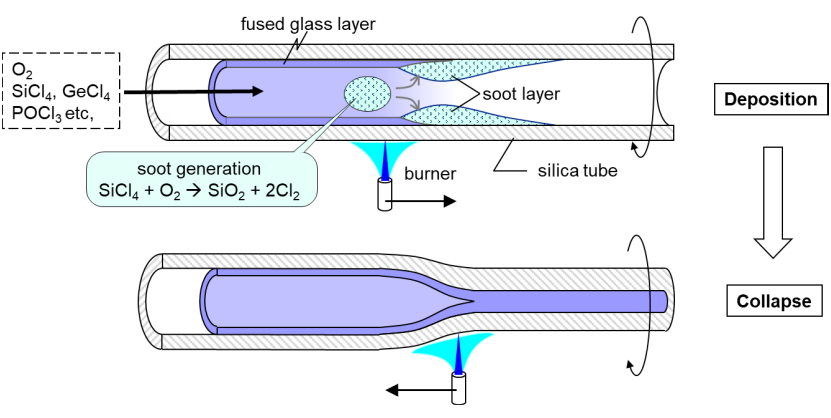

(b) The MCVD method

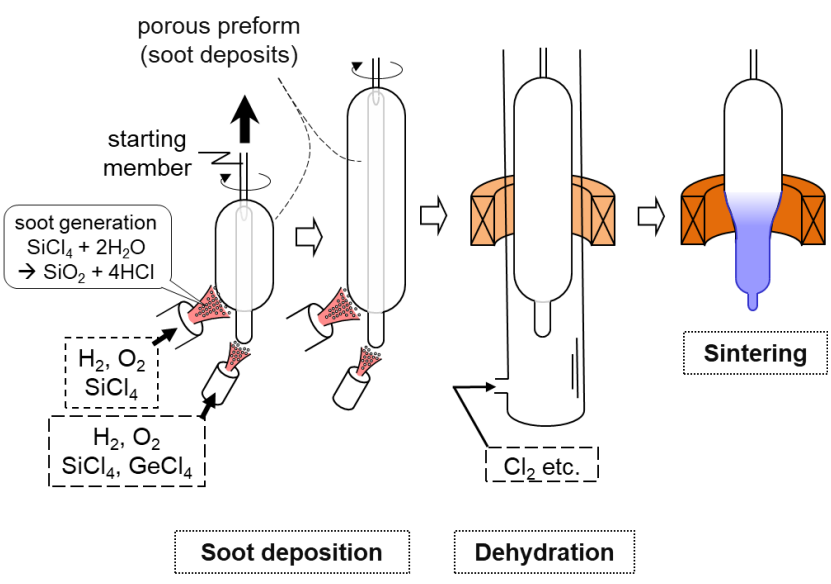

(c) The VAD method

Fig. 1 Preform manufacturing methods.

the US achieved a transmission loss of $2 \mathrm{~dB} / \mathrm{km}$ at $1.06 \mu \mathrm{m}$ utilizing the modified chemical vapor deposition (MCVD) method [11]. The core was doped with $\mathrm{GeO}_{2}$. In the MCVD method, as shown in Fig. 1(b), gaseous glass raw materials and oxygen are fed into a silica glass tube. The tube is externally heated by an oxyhydrogen burner to form a glass layer of a desired composition on the inner surface of the tube, and then the tube is shrunk in the radial direction to be solidified by additional heating, which is called the "collapse" process. Tasker et al. of Bell Laboratories fabricated a GI fiber using $\mathrm{B}_{2} \mathrm{O}_{3}$ to form parabolic refractive index distribution with a loss of $1.7 \mathrm{~dB} / \mathrm{km}$ at $1.05 \mu \mathrm{m}$, and a step index fiber with a $\mathrm{SiO}_{2}$ core and $\mathrm{B}_{2} \mathrm{O}_{3}$ added $\mathrm{SiO}_{2}$ cladding with a loss of $1.1 \mathrm{~dB} / \mathrm{km}$ at $1.02 \mu \mathrm{m}$ [12].

During the early stage of optical fiber development, which started from $20 \mathrm{~dB} / \mathrm{km}$ optical fiber, the main target for loss reduction was the reduction of absorption loss due to impurities. Hydroxy (OH-) groups and transition metals were the most important impurities particularly in the visible to near infrared (IR) region [8], [13]. As for the $\mathrm{OH}$-groups, the fundamental vibration of $\mathrm{OH}$ occurs at a wavelength of $2.7 \mu \mathrm{m}$, and its first overtone appears at $1.38 \mu \mathrm{m}$. The absorption loss at $1.24 \mu \mathrm{m}$ is due to the combination of the $\mathrm{OH}$ first overtone and the fundamental vibration of $\mathrm{SiO}_{4}$ tetrahedron. While these absorption losses due to the $\mathrm{OH}$ group had been a barrier to lowering the loss of the optical fiber, Horiguchi of NTT and Osanai of Fujikura achieved the loss of $0.47 \mathrm{~dB} / \mathrm{km}$ at $1.2 \mu \mathrm{m}$ by reducing the $\mathrm{OH}$ absorption loss with an optical fiber manufactured by the MCVD method in 1976 [14]. This fiber was a step-index type MM fiber with a $\mathrm{P}_{2} \mathrm{O}_{5}-\mathrm{SiO}_{2}$ core and a $\mathrm{B}_{2} \mathrm{O}_{3}-\mathrm{SiO}_{2}$ cladding. They paid attention to the purity of raw materials and gases, and the contamination from the raw material container. At the longer wavelength side, the loss was high due to the effect of the tail of IR absorption of B-O and P-O [15]. In 1979, Miya et al. of NTT achieved the loss of $0.20 \mathrm{~dB} / \mathrm{km}$ at $1.55 \mu \mathrm{m}$ with an SM fiber manufactured by the MCVD method [16], where $\mathrm{GeO}_{2}-\mathrm{SiO}_{2}$ was used for the core and $\mathrm{SiO}_{2}$ for the cladding to remove the effects of IR molecular vibrations of $\mathrm{B}-\mathrm{O}$ and $\mathrm{P}-\mathrm{O}$. Additionally, in the manufacturing process of the preform, the starting silica glass tube was heated to remove surface scratches, the glass deposition temperature was increased to sufficiently fuse the glass deposition layer so as to improve the structural uniformity of the optical fiber.

In 1977, the vapor phase axial deposition (VAD) method was invented as a preform manufacturing method by Izawa et al. of NTT [17]. The process of the VAD method is schematically illustrated in Fig. 1(c). Gaseous glass raw materials are fed to oxyhydrogen burners to generate soot by a flame hydrolysis reaction, and the soot deposits on the tip of the rotating starting member. The starting member is pulled upwards to axially form a porous preform, that is the deposited body of soot. The porous preform synthesized by a flame hydrolysis reaction contains a large amount of $\mathrm{OH}-$ group. Elmer et al. disclosed that $\mathrm{OH}$-groups in porous glass could be removed by heating in a gas atmosphere containing chlorine $\left(\mathrm{Cl}_{2}\right)$, where the $\mathrm{OH}$-groups are replaced with chlorine ions [18]. Accordingly, in order to achieve high purity, the porous preform manufactured by the VAD method is heated in an atmosphere containing $\mathrm{Cl}_{2}$, and further heated at a higher temperature to form a transparent glass preform. 
Table 1 Loss achieved from 1970 to 1981.

\begin{tabular}{l|c|c|c|c|c|c|c|}
\hline Year & $\begin{array}{c}\text { Loss } \\
(\mathrm{dB} / \mathrm{km})\end{array}$ & $\begin{array}{c}\text { Wavelength } \\
(\mu \mathrm{m})\end{array}$ & Method & $\begin{array}{c}\text { Core } \\
\text { Composition }\end{array}$ & $\begin{array}{c}\text { Fiber } \\
\text { Type }\end{array}$ & Ref. \\
\hline 1970 & 20 & 0.6328 & $\mathrm{IVD}^{[5]}{ }^{* 1}$ & $\mathrm{TiO}_{2}-\mathrm{SiO}_{2}{ }^{5]}$ & $\mathrm{SM}$ & {$[1]$} \\
\hline 1972 & 7 & 1.06 & --- & --- & $\mathrm{MM}$ & {$[7]$} \\
\hline 1973 & 4 & $0.8-0.85,1.05$ & --- & --- & $\mathrm{MM}$ & {$[8]$} \\
\hline 1974 & 2.0 & 1.06 & $\mathrm{MCVD}$ & $\mathrm{GeO}_{2}-\mathrm{SiO}_{2}{ }^{* 2}$ & $\mathrm{MM}$ & {$[11]$} \\
\hline 1974 & 1.7 & 1.04 & $\mathrm{MCVD}$ & $\mathrm{B}_{2} \mathrm{O}_{3}-\mathrm{SiO}_{2}{ }^{* 2}$ & $\mathrm{MM}$ & {$[12]$} \\
\hline 1974 & 1.1 & 1.02 & $\mathrm{MCVD}$ & $\mathrm{SiO}_{2}{ }^{* 2}$ & $\mathrm{MM}$ & {$[12]$} \\
\hline 1976 & 0.47 & 1.21 & $\mathrm{MCVD}$ & $\mathrm{P}_{2} \mathrm{O}_{5}-\mathrm{SiO}_{2}{ }^{* 2}$ & $\mathrm{MM}$ & {$[14]$} \\
\hline 1979 & 0.20 & 1.55 & $\mathrm{MCVD}$ & $\mathrm{GeO}_{2}-\mathrm{SiO}_{2}$ & $\mathrm{SM}$ & {$[16]$} \\
\hline 1981 & 0.20 & 1.55 & $\mathrm{VAD}$ & $\mathrm{GeO}_{2}-\mathrm{SiO}_{2}$ & $\mathrm{SM}$ & {$[21]$} \\
\hline *1 & $\mathrm{IVD}:$ Inside Vapor Deposition & & & \\
*2 & $\mathrm{Cladding}: \mathrm{B}_{2} \mathrm{O}_{3}-\mathrm{SiO}$ & & & \\
*3 & $\mathrm{SM}:$ Single-mode, MM : Multi-mode
\end{tabular}

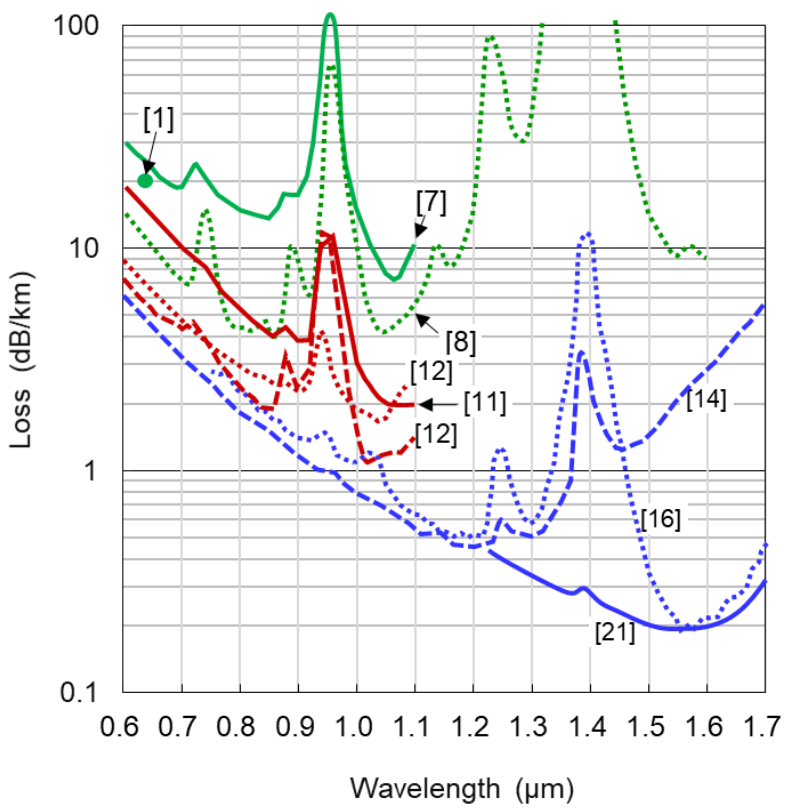

Fig. 2 Loss spectra from 1970 to 1981.

Moriyama et al. of Fujikura and Hanawa et al. of NTT reported "OH-free" fibers manufactured by the VAD method [19], [20], in which the losses due to residual OH-groups were less than the detectable level. The loss of the VAD fiber was also improved as that of the MCVD fiber, and an SM fiber with the loss of $0.20 \mathrm{~dB} / \mathrm{km}$ at $1.55 \mu \mathrm{m}$ was successfully fabricated by Tomaru et al. of NTT in 1981 [21].

The losses achieved from 1970 to1981 mentioned above are summarized in Table 1 and the loss spectra are overwritten in Fig. 2. It can be seen that the minimum loss window had shifted from $0.63 \mu \mathrm{m}$ to $1.55 \mu \mathrm{m}$ with the progress of the technology to remove $\mathrm{OH}$-groups.

\section{Formulation of Optical Fiber Loss Factors}

The transmission loss of an optical fiber $\alpha$ can be expressed as a function of wavelength $\lambda$ by

$$
\begin{aligned}
\alpha(\lambda)= & A / \lambda^{4}+B+C(\lambda)+D(\lambda) \\
& +E_{1} \exp \left(E_{2} / \lambda\right)+F_{1} \exp \left(-F_{2} / \lambda\right)
\end{aligned}
$$

$A / \lambda^{4}$ is a term that represents the intrinsic scattering loss of the material itself constituting the optical fiber. The scattering loss includes Rayleigh scattering loss due to fluctuations smaller than the order of the light wavelength in density and composition, Mie scattering due to fluctuations equal to or greater than the light wavelength, Brillouin scattering due to interaction with acoustic phonons, and Raman scattering due to interaction with molecular vibrations. Among them, Rayleigh scattering is dominant. Rayleigh scattering is inversely proportional to the fourth power of the wavelength $\lambda$, and $A$ is called Rayleigh scattering coefficient. Rayleigh scattering is separated into a term due to density fluctuation of glass, $A_{d} / \lambda^{4}$, and a term due to composition fluctuation, $A_{c} / \lambda^{4}$ as Eq. (2) [22].

$$
A / \lambda^{4}=A_{d} / \lambda^{4}+A_{c} / \lambda^{4}
$$

The term due to density fluctuation can be expressed by [23]

$$
A_{d} / \lambda^{4}=\frac{8 \pi^{3}}{3 \lambda^{4}} n^{8} p^{2} k T_{f} \beta_{T_{f}}
$$

where $n$ is the refractive index, $p$ is the photo-elastic constant, $k$ is Boltzmann's constant, $T_{f}$ is the fictive temperature, and $\beta_{T_{f}}$ is the isothermal compressibility. $T_{f}$ is defined as the temperature at which the glass would be in equilibrium if suddenly brought to that temperature from its given state [24], [25]. In other words, $T_{f}$ is the temperature at which liquid glass in equilibrium has the same degree of disorder as that for the glass tested.

$B$ is a term representing a structural imperfection loss, that is scattering loss caused by foreign materials and/or bubbles in the optical fiber, irregularity of the interface between the core and the cladding, and so on. Generally, $B$ does not depend on the wavelength.

$C(\lambda)$ is a term that represents the effect of absorption loss due to impurities.

$D(\lambda)$ is a term that represents the effect of absorption loss due to glass defects.

$E_{1} \exp \left(E_{2} / \lambda\right)$ is the influence of the ultraviolet (UV) absorption tail of glass. The empirical rule that the effect of electronic transition absorption on the edge is proportional to the exponential of photon energy is known as Urbach's rule [26]. In the case of $\mathrm{SiO}_{2}$ glass, it is negligible in the wavelength range used for optical communication systems.

$F_{1} \exp \left(-F_{2} / \lambda\right)$ is the influence of the infrared (IR) absorption of glass, that is, the tail of the absorption due to molecular vibration. Generally, the frequency peak of molecular vibration is inversely proportional to the square root of the reduced mass of the cation-oxygen pair. Therefore, as the glass component contains a lighter element, the influence of IR absorption to the near IR region used for optical communication systems becomes greater. Osanai et al. showed that IR absorption of $\mathrm{B}_{2} \mathrm{O}_{3}$-doped silica optical fiber is higher than that of $\mathrm{GeO}_{2}-\mathrm{SiO}_{2}$ core optical fiber [27]. In the case of $\mathrm{SiO}_{2}$ glass [28], the effect of IR absorption at a wavelength of $1.55 \mu \mathrm{m}$ is about $0.01 \mathrm{~dB} / \mathrm{km}$.

Since Rayleigh scattering is inversely proportional to the fourth power of the wavelength $\lambda$, Inada proposed plotting a loss spectrum of an optical fiber with the horizontal axis of $1 / \lambda^{4}$ as a convenient method to analyze the loss 


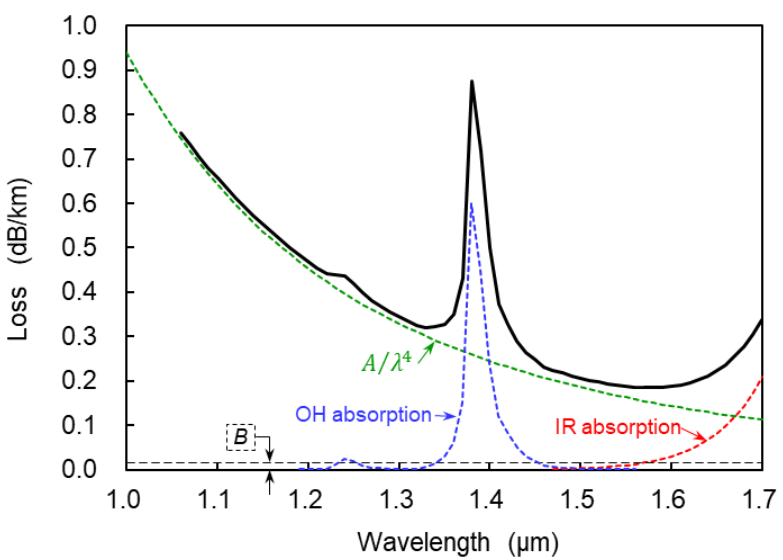

Fig. 3 Example of loss spectrum of typical SM fiber.

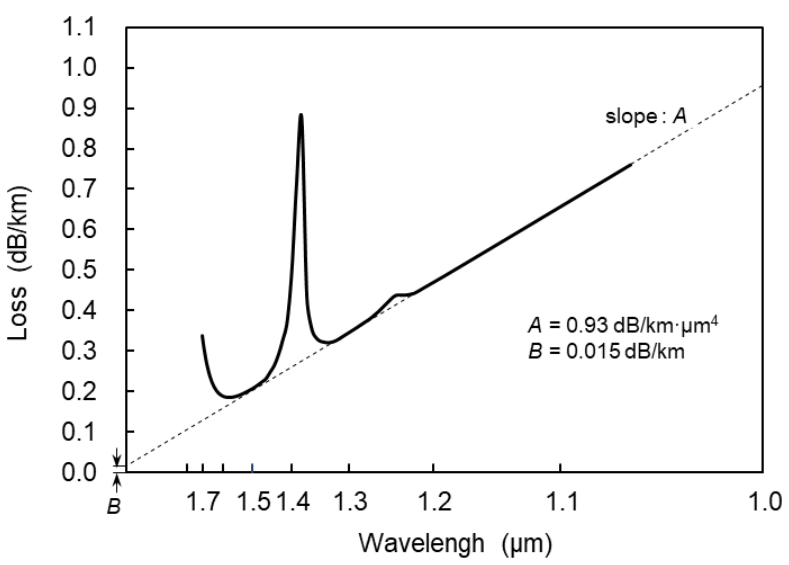

Fig. $41 / \lambda^{4}$ plotting of loss spectrum of typical SM fiber.

spectrum [29]. With this $1 / \lambda^{4}$ plotting, Rayleigh scattering coefficient $A$ can be obtained from the slope of the straight-line portion, and the y axis intercept of the straight line can be recognized as $B$. Figure 3 shows an example of typical loss spectrum of a standard SM fiber, and Fig. 4 is a $1 / \lambda^{4}$ plotting for the loss spectrum. In this example, $A=0.93 \mathrm{~dB} / \mathrm{km} \cdot \mu \mathrm{m}^{4}$, and $B=0.015 \mathrm{~dB} / \mathrm{km}$ are obtained by this method.

\section{Pure-Silica-Core Fiber}

\subsection{Development of Pure-Silica-Core SM Fibers}

For $\mathrm{GeO}_{2}-\mathrm{SiO}_{2}$ core optical fibers, Rayleigh scattering due to composition fluctuation increases with increase of $\mathrm{GeO}_{2}$ content [30]. It was said that the value of $0.20 \mathrm{~dB} / \mathrm{km}$ achieved with the conventional $\mathrm{GeO}_{2}-\mathrm{SiO}_{2}$ core optical fiber should be almost the theoretical limit.

In order to overcome the limit for the conventional fibers, Kanamori et al. developed a pure-silica-core SM fiber [31]. In this fiber, Rayleigh scattering due to composition fluctuations of $\mathrm{GeO}_{2}$ is suppressed by using pure silica glass as the core. As shown in Fig. 5, instead of using $\mathrm{GeO}_{2}$ which raises the refractive index of the core, fluorine $(\mathrm{F})$ is added to

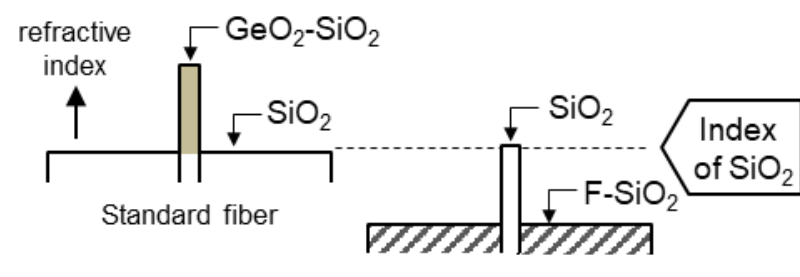

Pure-silica-core fiber

Fig.5 Structure of pure-silica-core SM fiber.

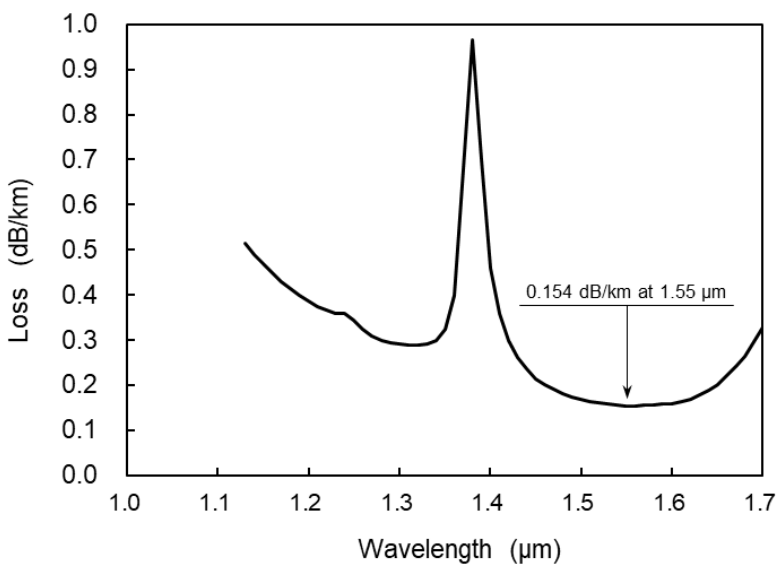

Fig. 6 Loss spectrum of pure-silica-core SM fiber.

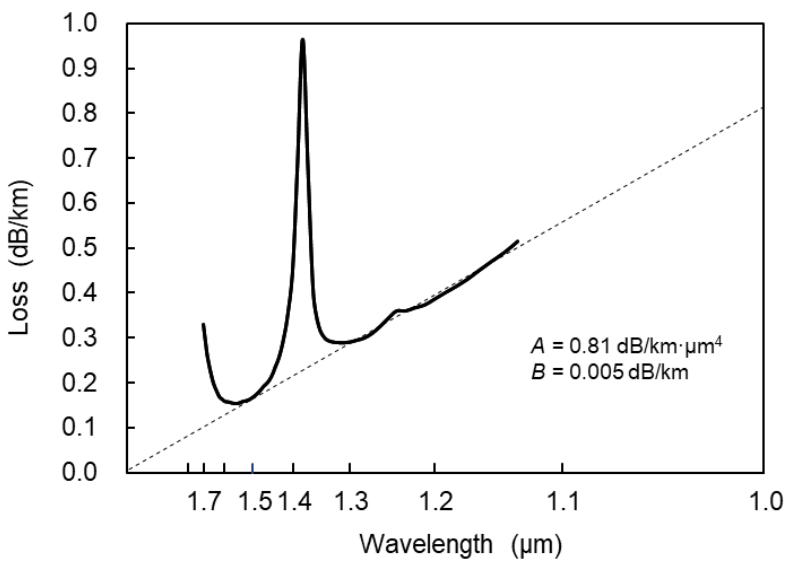

Fig. $71 / \lambda^{4}$ plotting of loss spectrum of pure-silica-core SM fiber

the cladding, which has the effect of lowering the refractive index.

With a pure-silica-core SM fiber, Yokota et al. demonstrated a record-low loss of $0.154 \mathrm{~dB} / \mathrm{km}$ achieved at a wavelength of $1.55 \mu \mathrm{m}$ [32]. Figure 6 shows the loss spectrum of the fiber, and Fig. 7 is $1 / \lambda^{4}$ plotting of the loss spectrum.

In addition to the low loss, the pure-silica-core SM fiber has special features that irreversible loss increase due to generation of $\mathrm{OH}$-groups induced by hydrogen penetration does not occur, and that loss increase due to $\gamma$-ray irradiation is suppressed as well [31]. Owing to these advantages, pure-silica-core SM fibers started to be employed for submarine cable applications that require high reliability as 
well as low loss.

\subsection{Residual Stress in Pure-Silica-Core SM Fiber}

For pure-silica-core SM fibers, the core has much higher viscosity than the F-doped cladding. Consequently, the drawing tension is concentrated to the core, which may cause high residual stress in the axial direction on the core. Accordingly, when the drawing condition is not appropriate, that means the drawing tension is too high, photo-elastic effect due to the residual tensile stress causes decrease of the refractive index of the core [33]. Hibino et al. reported the dependence of the relative refractive index difference on the drawing tension for pure-silica-core SM fibers [34], and clarified, by the Brillouin gain shift measurement, that it can be attributed to the residual stress [35]. Hibino et al. and Ohashi et al. observed not only the refractive index decrease of the core but increase of the loss with increasing high drawing tension [35], [36]. The mechanism of the loss increase induced by high drawing tension for pure-silicacore SM fiber was not clear, but slight fluctuation in drawing process might result in a structural imperfection loss.

The residual stress in the axial direction is expressed as sum of the mechanically induced stress and the thermal stress. The mechanically induced residual stress $\sigma_{j}$ can be expressed by [37]

$$
\sigma_{j}=F\left(\frac{\eta_{j}}{\sum_{i=1}^{n} A_{i} \eta_{i}}-\frac{E_{j}}{\sum_{i=1}^{n} A_{i} E_{i}}\right)
$$

In Eq. (4), $F$ is the drawing tension. The lower index $j(1 \leq$ $j \leq n$ ) indicates the portion in the fiber. $A_{j}, \eta_{j}$ and $E_{j}$ are the cross-sectional area, the viscosity and Young's modulus of the portion $j$, respectively, at the temperature where the fiber starts to behave elastically. If the fiber consists of just a core and a cladding, Eq. (4) becomes

$$
\begin{aligned}
& \sigma_{1}=F\left(\frac{\eta_{1}}{A_{1} \eta_{1}+A_{2} \eta_{2}}-\frac{E_{1}}{A_{1} E_{1}+A_{2} E_{2}}\right) \\
& \sigma_{2}=F\left(\frac{\eta_{2}}{A_{1} \eta_{1}+A_{2} \eta_{2}}-\frac{E_{2}}{A_{1} E_{1}+A_{2} E_{2}}\right)
\end{aligned}
$$

where, $j=1$ means core, and $j=2$ means cladding.

The thermal stress $\sigma_{t h}$ arising from the non-uniformity of thermal expansion coefficient can be expressed by

$$
\sigma_{t h}(r, T)=\int_{T_{\text {room }}}^{T^{*}} \frac{E(r, T)}{1-v(r, T)}\{\alpha(r, T)-c(T)\} d T
$$

where

$$
c(T)=\int_{0}^{R} \alpha(r, T) r d r
$$

In Eq. (5a), $T^{*}$ is a virtual temperature where stress starts to occur in drawing process. $\alpha(r, T)$ is the thermal expansion coefficient at radial position $r$ and temperature $T$, $E(r, T)$ and $v(r, T)$ are Young's modulus and Poisson's ratio, respectively. In case of pure-silica-core fibers with F-doped

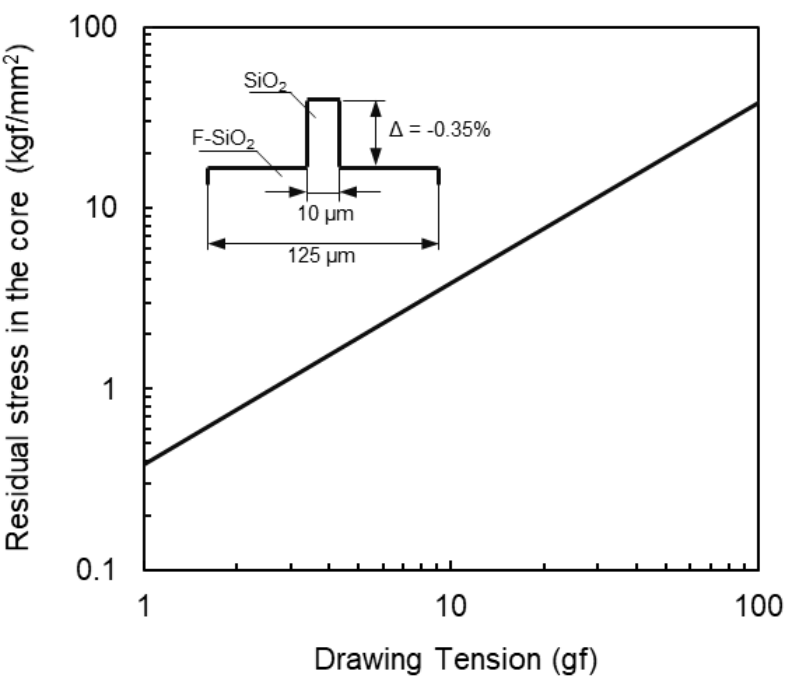

Fig. 8 Relationship between the drawing tension and the residual stress Residual stress is obtained for the fiber parameters shown in the inset.

cladding, difference of thermal expansion coefficient between pure-silica-core and F-doped cladding is small. Consequently, the thermal stress can be ignored, and the mechanically induced stress dominates the residual stress.

Figure 8 shows the relationship between the drawing tension and the residual stress in the core obtained from Eq. (4a) for the pure-silica-core/ $/ \mathrm{F}_{-} \mathrm{SiO}_{2}$ cladding fiber with a core diameter of $10 \mu \mathrm{m}$ and the relative refractive index difference of $-0.35 \%$, assuming the viscosity ratio $\eta_{\text {clad }} / \eta_{\text {core }}$ as 0.17 , which is read off Fig. 9 of the reference [37], and $E_{\text {clad }} / E_{\text {core }}=1$.

From the viewpoint that lower residual stress is better, it was considered the drawing tension should be lowered as much as possible. It means elevating the temperature of the drawing furnace, and/or decreasing the drawing speed. But these drawing conditions were not economical. Moreover, only this simple hypothesis could not lead to a clue for further loss reduction.

\section{Viscosity Matching}

Regarding loss factors of optical fibers, the concept of "viscosity matching" attracted attention at a certain period of early 1990s. At that time, dispersion-shifted fibers (DSFs) whose chromatic dispersion becomes zero at around $1.55 \mu \mathrm{m}$ wavelength region were being developed. In order to control the chromatic dispersion with keeping low bending loss as well as relatively large mode field diameter for easy splicing, a complex refractive index profile became necessary. In order to reduce the loss with the complex profile, it was considered smaller residual stress would be advantageous, and Tateda et al. proposed a design method that yielded arbitrary refractive index profiles with homogeneous viscosity throughout the cross section by tuning the content of $\mathrm{Ge}$ and $\mathrm{F}$ in $\mathrm{GeO}_{2}-\mathrm{F}-\mathrm{SiO}_{2}$ glass systems [38]. Ohashi et al. investigated the relationship between the viscosity distribution and the loss, and found that the viscosity matching 
at the core/cladding interface is important to reduce the loss [39].

\section{IR Transmission Fiber}

Aiming at realizing an extremely low loss optical fiber, IR transmission optical fibers made of IR transmissive material were investigated in the 1980s to 1990s. As shown in Fig. 9, IR transmissive materials have the absorption band due to molecular vibration at the longer wavelength region than silica. Since the main factor of the loss of the optical fiber is Rayleigh scattering, which is inversely proportional to the fourth power of the wavelength, the achievable loss of IR transmission fiber was expected to be an order of magnitude lower than that of silica fibers.

The materials used were IR transparent glass such as fluoride glass, halide glass, chalcogenide glass and the like. Optical fibers using these materials had been proposed from the 1970 s and were expected to realize ultra-low loss of 0.01 to $0.001 \mathrm{~dB} / \mathrm{km}$ or less in the wavelength range of 2 to $10 \mu \mathrm{m}$. Among them, $\mathrm{ZrF}_{4}$ based fluoride glass was most actively studied [40]. However, unlike silica glass, these IR transmissive glasses tend to crystallize, and microcrystals are easily formed during the cooling process in the optical fiber manufacturing. As a result, the IR transmission fibers showed large structural imperfection loss. Indeed, the fibers with a loss less than $1 \mathrm{~dB} / \mathrm{km}$ were developed [41], [42], but the loss lower than silica fibers have not been realized. The lowest loss record was $0.45 \mathrm{~dB} / \mathrm{km}$ at $2.35 \mu \mathrm{m}$ reported by Szebesta et al. with $\mathrm{ZrF}_{4}$ based glass fiber [43], but the fiber length was as short as $60 \mathrm{~m}$. Although it is considered to be difficult to use fluoride glass fibers for long-distance optical communication, it has been employed as a host fiber for a rare-earth-doped optical fiber amplifier. It is because fluoride glasses have low phonon energy and can suppress nonradiative transition due to multi-phonon absorption from the excitation level of the rare-earth elements, leading to high amplification performance [44].

\section{Reduction in Rayleigh Scattering of Silica Fibers}

\subsection{Evaluation of $T_{f}$ and Rayleigh Scattering}

In the 1990 s, it was widely recognized that it is necessary to reduce Rayleigh scattering loss, which accounts for $80 \%$ or more of the total loss, in order to reduce further the loss of the optical fiber. As mentioned above, Rayleigh scattering loss is expressed as the sum of the term due to density fluctuation of glass, $A_{d} / \lambda^{4}$, and a term due to composition fluctuation, $A_{c} / \lambda^{4}$.

The way to reduce $A_{c} / \lambda^{4}$ is simple. The answer is the pure-silica-core fiber. Researchers, therefore, put much effort to reduce $A_{d} / \lambda^{4}$.

Glass is a solid frozen from the liquid state. In the liquid state, the density fluctuation increases as the temperature increases. The density fluctuation of glass can be expressed by $T_{f}$ as a scale, which means the temperature of the frozen

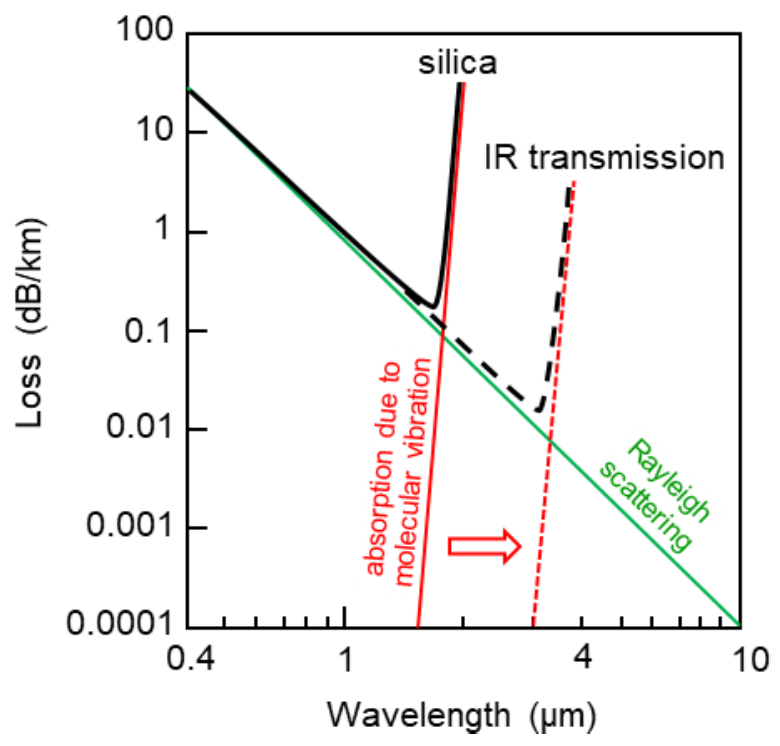

Fig. 9 Concept of loss reduction with IR transmission fibers.

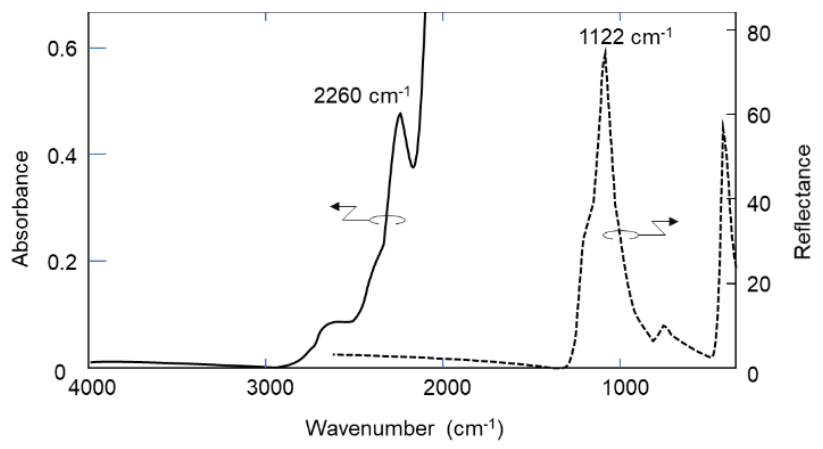

Fig. 10 IR transmission/reflection spectra of silica glass.

liquid state (or equilibrium state). $T_{f}$ can be measured using an IR transmission/absorption spectrum [25], [45] or a Raman scattering spectrum [45], [46]. The IR absorption spectrum of silica glass is shown in Fig. 10 and the Raman scattering spectrum of silica glass is shown in Fig. 11.

In Fig. 10, the $1122 \mathrm{~cm}^{-1}$ band of the reflection spectrum is the stretching vibration band of Si-O-Si bridges, and the $2260 \mathrm{~cm}^{-1}$ absorption band of the IR transmission spectrum is the overtone of the vibration [25]. When the sample is heated to a specified temperature corresponding to $T_{f}$, held for a sufficiently long time and rapidly cooled, the peak wavenumbers of the bands of $1122 \mathrm{~cm}^{-1}$ and $2260 \mathrm{~cm}^{-1}$ shift depending on $T_{f}$ [25], [45]-[49]. Accordingly, from the precise measurement of the peak wavenumber of IR absorption, $T_{f}$ of silica glass can be estimated.

In the Raman spectrum shown in Fig. 11, broad peaks labeled $\omega_{1}, \omega_{3}, \omega_{4}(\mathrm{TO})$ and $\omega_{4}(\mathrm{LO})$ are identified as vibrations of glass network [46]. On the other hand, $\mathrm{D}_{1}$ and $\mathrm{D}_{2}$ are the so-called defect lines, interpreted as occurring from the symmetric stretch of planar four-fold and threefold ring, respectively [46], [47], [50] as shown in Fig. 12. Six-fold ring is normal for $\mathrm{SiO}_{2}$ glass, and three and four- 


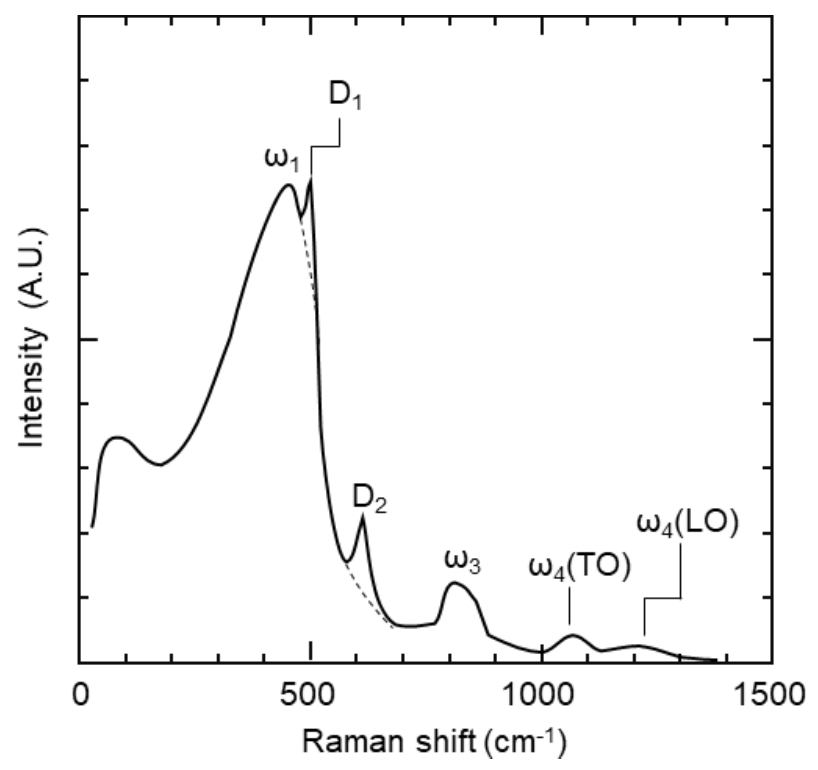

Fig. 11 Raman spectrum of silica glass.
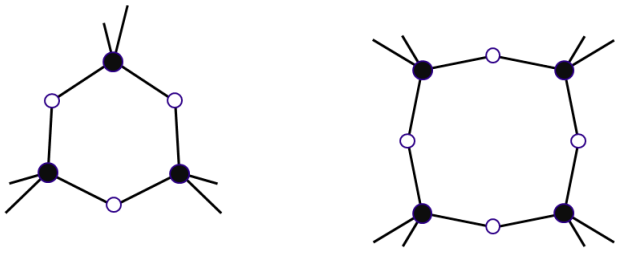

planar 3-fold ring

planar 4-fold ring

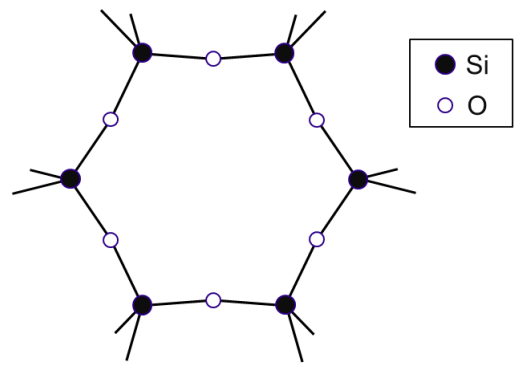

planar 6-fold ring

Fig. 12 Planar rings of $\mathrm{SiO}_{2}$ glass network [48].

fold rings increase with increase of irregularity of $\mathrm{SiO}_{2}$ network. Hence, from the intensity of $\mathrm{D}_{1}$ or $\mathrm{D}_{2}$, degree of disorder of network corresponding to $T_{f}$ can be estimated.

Rayleigh scattering can be directly measured by irradiating a sample with a laser beam such as Ar ion laser and detecting the intensity of scattered laser beam with a photomultiplier [51]-[53]. If devised, it is possible to measure Rayleigh scattering even in the drawn fiber state [54]. It has been confirmed that the scattering intensity of bulk glass has a nearly linear relationship with $T_{f}$ [45], [55].

For bulk silica glasses, Rayleigh scattering coefficient $A$ in Eq. (1) is reported to be $0.6 \mathrm{~dB} / \mathrm{km} \cdot \mu \mathrm{m}^{4}$ [52], and $T_{f}$ is usually $1400^{\circ} \mathrm{C}$ or below. On the other hand, $A$ of optical fibers are 0.8 to $0.9 \mathrm{~dB} / \mathrm{km} \cdot \mu \mathrm{m}^{4}$, as shown in Fig. 4 and
Fig. 7. As for $T_{f}$ of a silica fiber, Sakaguchi et al. reported it is around $1600^{\circ} \mathrm{C}[56]$. Therefore, it was considered that if the $T_{f}$ of the optical fiber could be lowered, the loss of the optical fiber would be reduced.

In the optical fiber drawing process, since glass is generally cooled at a cooling rate of several thousand ${ }^{\circ} \mathrm{C} / \mathrm{sec}$, a state with large density fluctuations is frozen. In order to lower $T_{f}$ of the optical fiber to reduce the loss, it is important to promote the structural relaxation of the glass. That is, it was considered that if the structural relaxation of the glass could be promoted, the lower temperature state where the density fluctuation becomes smaller could be frozen in the cooling process, resulting in the lower loss of the optical fiber.

\subsection{Effect of Dopant}

The first method to promote glass relaxation is to add dopants that have the effect of reducing the viscosity of glass. Of course, the addition of an excessive amount of dopant increases the density fluctuation, which has an adverse effect on Rayleigh scattering reduction. With this in mind, various researches to verify the dopant addition effect were conducted as below.

Tajima et al. confirmed the Rayleigh scattering loss of $\mathrm{P}_{2} \mathrm{O}_{5}-\mathrm{F}-\mathrm{SiO}_{2}$ glass $\left(\mathrm{P}_{2} \mathrm{O}_{5}: 8.5\right.$ wt.\%, $\left.\mathrm{F}: 0.3 \mathrm{wt} . \%\right)$ is 0.8 times lower than that of pure $\mathrm{SiO}_{2}$ glass [57], and Rayleigh scattering coefficient of $0.66 \mathrm{~dB} / \mathrm{km} \cdot \mu \mathrm{m}^{4}$ was obtained for a $\mathrm{P}_{2} \mathrm{O}_{5}-\mathrm{SiO}_{2}$ core $\mathrm{SM}$ fiber [58]. Unfortunately, the fiber showed a structural imperfection loss as high as $0.36 \mathrm{~dB} / \mathrm{km}$, which was attributed to viscosity mismatch between the core and the cladding.

Lines reported Rayleigh scattering loss in the bulk state was reduced by up to $20 \%$ compared to pure $\mathrm{SiO}_{2}$ glass by adding alkali or alkaline earth elements [59]. Saito et al. proposed the method to dope $\mathrm{SiO}_{2}$ with only $10 \mathrm{wt}$. ppm of $\mathrm{Na}_{2} \mathrm{O}$, by which scattering loss could be reduced by $13 \%$ [60].

Fluorine (F) had gathered attention because of the effect to lower viscosity from the viewpoint of imperfection loss induced by viscosity mismatch. Ogai et al. demonstrated very low loss of $0.156 \mathrm{~dB} / \mathrm{km}$ by an SM fiber with $\mathrm{SiO}_{2}$ core slightly doped with $\mathrm{F}$ [61], and Ohashi et al. reported viscosity matching in the cross section of the fiber from the core to the cladding by utilizing $\mathrm{F}$ in order to reduce structural imperfection loss [39]. At that time, they did not mention the effect of $\mathrm{F}$ to lower $T_{f}$. Afterwards, Lines pointed out the possibility of $\mathrm{F}$ to lower $T_{f}$ [62], and Saito, Kakiuchida, and Shimodaira et al. conducted basic researches of $\mathrm{F}-\mathrm{SiO}_{2}$, regarding effect of $\mathrm{F}$ to $T_{f}$ by analyzing the specific band of Raman spectrum [47] as well as IR spectrum [63], [64]. Saito found chlorine (Cl) was also has the effect to promote relaxation of silica [65]. 


\subsection{Heat Treatment}

The second method to promote glass relaxation is heat treatment of drawn optical fibers. Sakaguchi et al. analyzed the end face of drawn optical fibers by Raman spectroscopy [56]. They found that its $T_{f}$ was $1600^{\circ} \mathrm{C}$ as drawn state, and that it was reduced to $1400^{\circ} \mathrm{C}$ by heating the optical fiber piece. Although reheating drawn optical fibers was not practically applicable, this result was an important clue to realize ultra-low-loss fibers.

Tajima et al. have shown that the loss of a standard $\mathrm{GeO}_{2}-\mathrm{SiO}_{2}$ core $\mathrm{SM}$ fiber could be reduced to $0.16 \mathrm{~dB} / \mathrm{km}$ by lowering the temperature of the drawing furnace to the limit at which drawing was possible [66]. In Tajima's work, drawing speed was $1 \mathrm{~m} / \mathrm{sec}$ [67] and it was difficult to directly put it into practical use from the viewpoint of productivity.

Saito et al. proposed a method to reduce the loss of an optical fiber by focusing on the cooling process during drawing [68], where an annealing furnace was set beneath a drawing furnace. The annealing furnace lowers the cooling rate of the optical fiber, and it was estimated that the transmission loss of the optical fiber could be reduced below $0.141 \mathrm{~dB} / \mathrm{km}$ with an annealing temperature of $1567^{\circ} \mathrm{C}$ and an annealing time of $1 \mathrm{sec}$.

\section{Loss Reduction of Commercial Fibers}

\subsection{Growing Needs of Low-Loss Fiber}

Development of low-loss optical fibers at the mass production level has been activated since 2010 with the practical application of digital coherent technology. The impact of the digital coherent technology on optical fibers was very significant in long haul transmission systems, especially for transoceanic submarine cable systems.

Digital coherent technology allows the linear waveform distortion due to chromatic dispersion and dynamic polarization dispersion fluctuation that occur during propagation in the optical fiber can be corrected by the digital signal processor at the receiving end. In the dense wavelength division multiplexing (DWDM) transmission systems before the advent of the digital coherent technology, the requirement on the chromatic dispersion characteristics of the optical fiber became stringent, and it was required to accurately form the refractive index distribution structure of the optical fiber into a three- to four-fold annual ring shape. It was also required to thoroughly reduce polarization dispersion. However, with the advent of digital coherent technology, the requirements for chromatic dispersion and polarization dispersion of optical fibers were relaxed. Instead, the low loss and suppression of nonlinear waveform distortion became to be strongly required. In parallel, the number of transoceanic optical submarine cable projects have continued to increase since 2013, when cloud services became popular on a global scale and borders began to disappear for

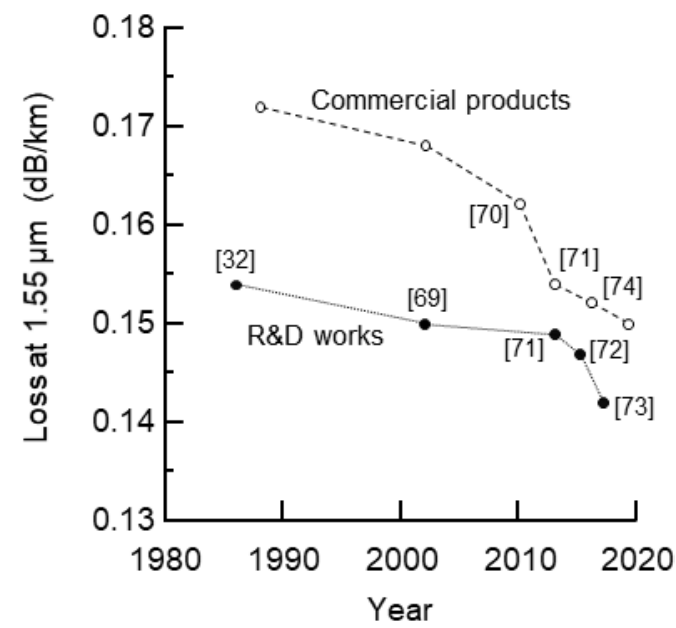

Fig. 13 Loss transition of pure-silica-core fibers

data exchange. Thus, digital coherent technology has also been applied to submarine systems, and the required ultralow-loss optical fiber has come into the spotlight.

\subsection{Ultra-Low-Loss Fibers of Recent Date}

Figure 13 shows the transition of loss reduction of optical fibers under the background as mentioned above. The loss improvement has been accelerated in the 2010s. Eventually, in 2017, Tamura et al. reported the record-low loss of 0.1419 $\mathrm{dB} / \mathrm{km}$ obtained at $1.56 \mu \mathrm{m}$ [73].

As shown in Fig. 13, not only the top data achieved in R\&D work but also the transmission loss of mass-produced products has been improved, and ultra-low-loss products of $0.150 \mathrm{~dB} / \mathrm{km}$ at $1.55 \mu \mathrm{m}$ are now being manufactured and commercialized.

The loss spectrum for the fiber which showed the lowest loss record is shown in Fig. 14. The loss at $1.55 \mu \mathrm{m}$ was $0.1424 \mathrm{~dB} / \mathrm{km}$. The loss was realized with an optical fiber, of which core was doped with small amount of fluorine as the inset in Fig. 14.

Figure 15 shows the relationship between $T_{f}$ and Rayleigh scattering coefficient in pure-silica-core fibers [75]. The fictive temperature was deduced from the normalized peak area of $D_{2} / \omega_{3}$ in Raman spectrum averaged over the fiber cross section of $100 \mu \mathrm{m}$, compared with that for the calibration sample with known $T_{f}$. In Fig. 15, Rayleigh scattering coefficient shows a good correlation with $T_{f}$.

In addition, the fiber with the record-low-loss has a large effective core area $A_{\text {eff }}$ of $147 \mu \mathrm{m}^{2}$ in order to realize the low nonlinearity required for digital coherent communication systems. In general, the larger $A_{e f f}$, the higher microbending loss, which corresponds to the sensitivity to the small deformation of the glass induced by the lateral pressure when accommodated in a cable. In order to keep the microbending loss low enough, a new soft primary coating with a reduced elastic modulus, which sufficiently absorbs lateral force and protects the glass fiber, has been developed. Figure 16 shows the dependence of microbending loss on 


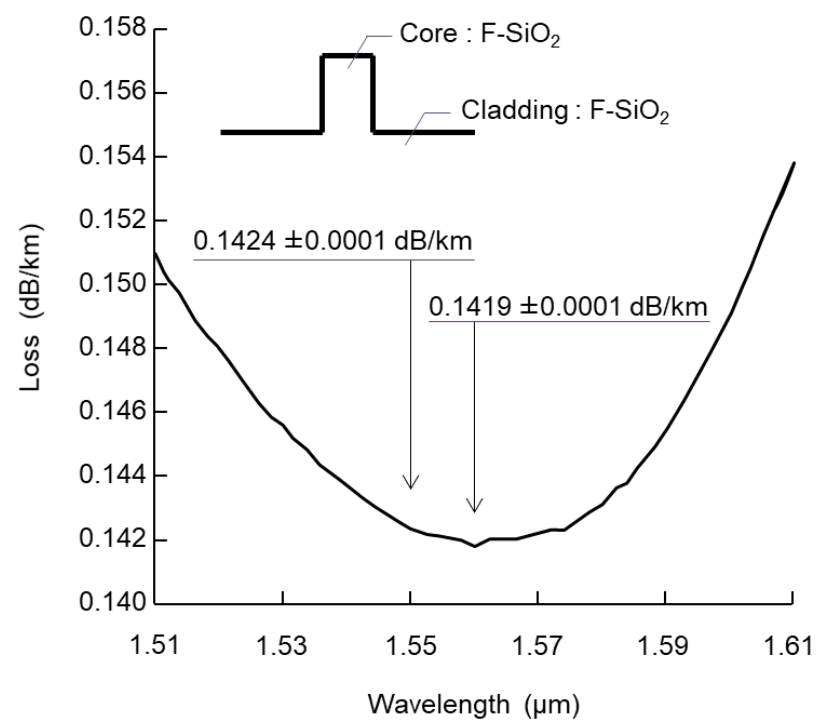

Fig. 14 Loss spectrum of the fiber with the record-low loss.

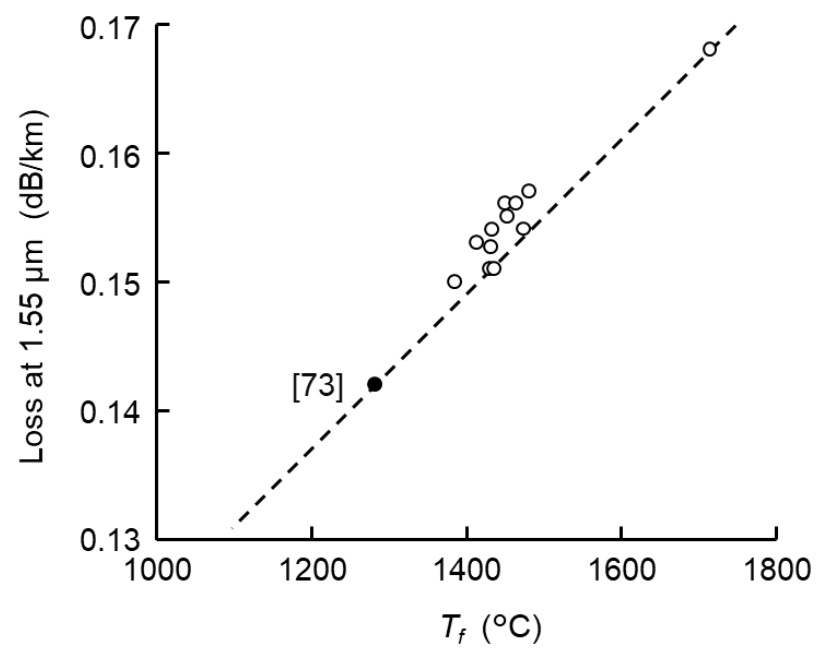

Fig. 15 Relationship between loss of pure-silica-core fibers and $T_{f}$.

$A_{\text {eff }}$ for fibers with the new coating compared with the conventional coating [77]. The microbending loss was measured by the wire mesh drum method [76]. It was confirmed that the microbending loss has been improved to as low as $0.1 \mathrm{~dB} / \mathrm{km}$, which is considered to be low enough for usual submarine cables, even with a large $A_{\text {eff }}$ of around $150 \mu \mathrm{m}^{2}$ owing to the new primary coating.

\subsection{Impact of Ultra-Low-Loss Fiber on System Perfor- mance}

Lower loss of optical fibers is surely beneficial for transoceanic systems, because the fiber loss needs to be compensated by large number of amplifiers that increase the noise, cost, and power consumption of the system. Hirano et al. discussed the benefits of reduced loss by the theory of fiber figure of merit (FOM) [71], [73]. In this theory, Q-factor can be estimated from the fiber loss, $A_{e f f}$,

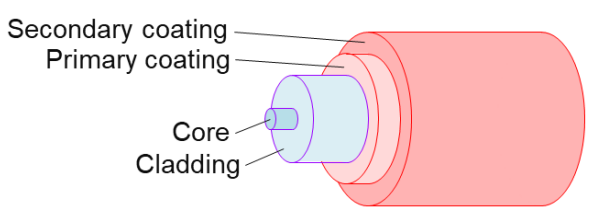

(a) Polymer coating surrounding glass of optical fiber

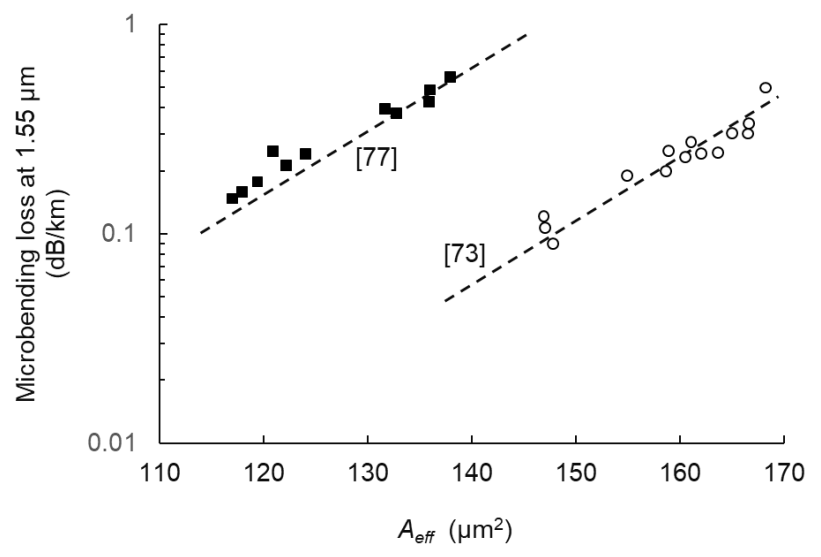

(b) Relationship between microbending loss and $A_{\text {eff }}$

Fig. 16 Microbending loss improvement.

Table 2 Example of reduction in repeater numbers of $10,000 \mathrm{~km}$ transoceanic systems by loss reduction.

\begin{tabular}{|c|c|c|c|c|}
\hline ref & $\begin{array}{c}\text { Loss } \\
\text { at } 1.55 \mu \mathrm{m}\end{array}$ & $A_{\text {eff }}$ & Span length & $\begin{array}{c}\text { Number of } \\
\text { repeaters }\end{array}$ \\
\hline$[71]$ & $0.149 \mathrm{~dB} / \mathrm{km}$ & $135 \mu \mathrm{m}^{2}$ & $60 \mathrm{~km}$ & 166 \\
\hline$[72]$ & $0.1467 \mathrm{~dB} / \mathrm{km}$ & $148 \mu \mathrm{m}^{2}$ & $67 \mathrm{~km}$ & 148 \\
\hline$[73]$ & $0.1424 \mathrm{~dB} / \mathrm{km}$ & $147 \mu \mathrm{m}^{2}$ & $72 \mathrm{~km}$ & 138 \\
\hline
\end{tabular}

Assuming 10,000 km, 8QAM-150Gbps (Q $\geq 7.0 \mathrm{~dB})$ system

and the span length. Table 2 shows an example of effect of loss reduction for reduction in repeater numbers in a $10,000 \mathrm{~km}$ transoceanic system that transmits 8QAM$150 \mathrm{G}$ signals with minimum required Q-factor of $7.0 \mathrm{~dB}$. The ultra-low loss fiber [73] can support a span of $72 \mathrm{~km}$, that is $6 \%$ longer than that for previous record fiber [72].

\subsection{Multi-Core Fiber (MCF)}

In order to meet increasing demand for the transmission capacity of a transoceanic submarine system, increase of fiber count in a submarine cables is one important challenge. For this purpose, a multi-core fiber (MCF), which has plural cores in one fiber, is now attracting rising attentions, and loss reduction is an important issue for MCFs as well. Hayashi et al. has reported the lowest loss of $0.158 \mathrm{~dB} / \mathrm{km}$ at $1.55 \mu \mathrm{m}$ for MCF with a coupled four core structure [79], and Tamura et al. has reported the loss of $0.162 \mathrm{~dB} / \mathrm{km}$ at $1.55 \mu \mathrm{m}$ with an uncoupled two core structure [80]. 


\section{Conclusion}

The history of loss reduction for silica optical fibers from the first report of $20 \mathrm{~dB} / \mathrm{km}$ by Corning in 1970 to the current record-low loss of $0.1419 \mathrm{~dB} / \mathrm{km}$ was reviewed. In 1970 1981, removal of impurities, especially OH-groups, was the main barrier to loss reduction, and eventually $0.20 \mathrm{~dB} / \mathrm{km}$ was achieved for $\mathrm{GeO}_{2}-\mathrm{SiO}_{2}$ core $\mathrm{SM}$ fibers. Subsequently, in 1986 , the loss of $0.154 \mathrm{~dB} / \mathrm{km}$ was achieved with a puresilica-core SM fiber by suppressing Rayleigh scattering due to composition fluctuation. In the 1990s and early 2000s, studies on reducing Rayleigh scattering due to density fluctuation were actively conducted by utilizing IR and Raman spectroscopy. Now, ultra-low-loss fibers with the loss of $0.150 \mathrm{~dB} / \mathrm{km}$ are commercially available in trans-oceanic submarine cable systems.

\section{References}

[1] F.P. Kapron, D.B. Keck, and R.D. Maurer, "Radiation losses in glass optical waveguides,” Appl. Phys. Lett., vol.17, no.10, pp.423-425, 1970

[2] I. Hayashi, M.B. Panish, P.W. Foy, and S. Sumski, "Junction lasers which operate continuously at room temperature,” Appl. Phys. Lett., vol.17, no.3, pp.109-111, 1970.

[3] K.C. Kao and G.A. Hockham, "Dielectric-fibre surface waveguides for optical frequencies," Proc. IEE, vol.113, no.7, pp.1151-1158, 1966.

[4] T. Uchida, M. Furukawa, I. Kitano, K. Koizumi, and H. Matsumura, "Optical characteristics of light-focusing fiber guide and its applications," J. Quant. Electron., vol.QE-6, no.10, pp.606-612, 1970.

[5] J. Hecht, City of Light: The Story of Fiber Optics, Oxford Univ. Press, 1999.

[6] R.D. Maurer and P.C. Schultz, "Germania containing optical waveguide,” U.S. Patent, 3,884,550, May 1975.

[7] D.B. Keck, P.C. Schultz, and F. Zimar, "Attenuation of multimode glass optical waveguides," Appl. Phys. Lett., vol.21, no.5, pp.215217, 1972.

[8] D.B. Keck, R.D. Maurer, and P.C. Schultz, "On the ultimate lower limit of attenuation in glass optical waveguides," Appl. Phys. Lett., vol.22, no.7, pp.307-309, 1973.

[9] R.D. DeLuca, "Method of making optical waveguides," U.S. Patent 3,933,454, Jan. 1976

[10] P.C. Schultz, "Fabrication of optical waveguides by the outside vapor deposition process," Proc. IEEE, vol.68, no.10, pp.1187-1190, 1980.

[11] J.B. MacChesney, P.B. O'Connor, F.V. Di Marcello, J.R. Simpson, and P.D. Lazay, "Preparation of low loss optical fibers using simultaneous vapor phase deposition and fusion," 10th Inter. Congr. on Glass Kyoto, 6-40-45, July 1974.

[12] G.W. Tasker and W.G. French, "Low-loss optical waveguide with pure fused $\mathrm{SiO}_{2}$ cores," IEEE Proc. Lett., vol.62, no.9, pp.12811282, 1974

[13] P.C. Schultz, "Optical absorption of the transition elements in vitreous silica,” J. Am. Ceram. Soc., vol.57, no.7, pp.309-313, 1974.

[14] M. Horiguchi and H. Osanai, "Spectral losses of low-OH-content optical fibres," Electron. Lett., vol.12, no.12, pp.310-312, 1976.

[15] T. Izawa, N. Shibata, and A. Takeda, "Optical attenuation in pure and doped fused silica in the IR wavelength region," Appl. Phys. Lett., vol.31, no.1, pp.33-35, 1977.

[16] T. Miya, Y. Terunuma, T. Hosaka, and T. Miyashita, "Ultimate lowloss single-mode fibre at $1.55 \mu \mathrm{m}$," Electron. Lett., vol.15, no.4, pp.106-108, 1979.
[17] T. Izawa, S. Kobayashi, S. Sudo, and F. Hanawa, "Continuous fabrication of high silica fiber preform,” Tech. Dig. Int. Conf. Integrated Optics and Optical Fiber Comm., p.375, July 1977.

[18] T.H. Elmer and M.E. Nordberg, "Method of treating a porous, high silica content glass," U.S. patent 3,459,522, Aug. 1969.

[19] T. Moriyama, O. Fukuda, K. Sanada. K. Inada, T. Edahiro, and K. Chida, "Ultimately low OH content V.A.D. optical fibres," Electron. Lett., vol.16, no.18, pp.698-699, 1980.

[20] F. Hanawa, S. Sudo, M. Kawachi, and M. Nakahara, "Fabrication of completely OH-free V.A.D. fibre,” Electron. Lett., vol.16, no.18, pp.699-700, 1980.

[21] S. Tomaru, M. Yasu, M. Kawachi, and T. Edahiro, "VAD single mode fibre with $0.2 \mathrm{~dB} / \mathrm{km}$ loss," Electron. Lett., vol.17, no.2, pp.92-93, 1981.

[22] M.E. Lines, "Scattering losses in optic fiber materials. I. A new parametrization," J. Appl. Phys., vol.55, no.11, pp.4052-4057, 1984.

[23] D.A. Pinnow, T.C. Rich, F.W. Ostermayer, Jr., and M. DiDomenico, Jr., "Fundamental optical attenuation limits in the liquid and glassy state with application to fiber optical waveguide materials," Appl. Phys. Lett., vol.22, no.10, pp.527-529, 1973.

[24] A.Q. Tool, "Relation between inelastic deformability and thermal expansion of glass in its annealing range," J. Am. Ceram. Soc., vol.29, no.9, pp.240-253, 1949.

[25] A. Agarwal, K.M. Davis, and M. Tomozawa, "A simple IR spectroscopic method for determining fictive temperature of silica glasses," J. Non-Cryst. Solids, vol.185, no.1-2, pp.191-198, 1995.

[26] F. Urbach, "The log-wavelength edge of photographic sensitivity and of the electronic absorption of solids," Phys. Rev., vol.92, p. $1324,1953$.

[27] H. Osanai, T. Shioda, T. Moriyama, S. Araki, M. Horiguchi, T. Izawa, and H. Takata, "Effect of dopants on transmission loss of lowOH-content optical fibres," Electron. Lett., vol.12, no.21, pp.549$550,1976$.

[28] R. Olshansky, "Propagation in glass optical waveguides," Rev. Mod. Phys., vol.51, no.2, pp.341-367, 1979.

[29] K. Inada, "A new graphical method relating to optical fiber attenuation," Opt. Commun., vol.19, no.3, pp.437-439, 1976.

[30] K. Yoshida, Y. Furui, S. Sentsui, and T. Kuroha, "Low-loss fibre prepared under high deposition rate by modified C.V.D. technique," Electron. Lett., vol.13, no.20, pp.608-610, 1977.

[31] H. Kanamori, H. Yokota, G. Tanaka, M. Watanabe, Y. Ishiguro, I. Yoshida, T. Kakii, S. Itoh, Y. Asano, and S. Tanaka, "Transmission characteristics and reliability of pure-silica-core single-mode fibers," J. Lightwave Tech., vol.LT-4, no.8, pp.1144-1150, 1986.

[32] H. Yokota, H. Kanamori, Y. Ishiguro, G. Tanaka, S. Tanaka, H. Takada, M. Watanabe, S. Suzuki, K. Yano, M. Hoshikawa, and H. Shimba, "Ultra-low-loss pure-silica-core single-mode fiber and transmission experiment," Proc. Opt. Fiber Comm. Conf., PD3, pp.11-18, Feb. 1986.

[33] Y. Ohga, E. Sasaoka, A. Urano, H. Kanamori, and H. Yokota, "Influence of drawing conditions on the refractive-index profile and residual stress in pure silica core single-mode fibers," Proc. Opt. Fiber Comm. Conf., 1989, THI2, Feb. 1989.

[34] Y. Hibino, F. Hanawa, and M. Horiguchi, "Drawing-induced residual stress effects on optical characteristics in pure-silica-core singlemode fibers," J. Appl. Phys., vol.65, no.1, pp.30-34, 1989.

[35] Y. Hibino, T. Edahiro, T. Horiguchi, Y. Azuma, and N. Shibata, "Evaluation of residual stress and viscosity in $\mathrm{SiO}_{2}$-core $/ \mathrm{F}-\mathrm{SiO}_{2}$ clad single-mode optical fibers from Brillouin gain spectra," J. Appl. Phys., vol.66, no.9, pp.4049-4052, 1989.

[36] M. Ohashi, K. Shiraki, and K. Tajima, "Optical loss property of silica-based single-mode fibers," J. Lightwave Technol., vol.10, no.5, pp.539-543, 1992.

[37] P.K. Bachmann, W. Hermann, H. Wehr, and D.U. Wiechert, "Stress in optical waveguides 2: Fibers," Appl. Opt., vol.26, no.7, pp.11751182, 1987. 
[38] M. Tateda, M. Ohashi, K. Tajima, and K. Shiraki, "Design of viscosity-matched optical fibers," IEEE Photon. Tech. Lett., vol.4, no.9, pp.1023-1025, 1992.

[39] M. Ohashi, M. Tateda, K. Shiraki, and K. Tajima, "Imperfection loss reduction in viscosity-matched optical fibers," IEEE Photon. Technol. Lett., vol.5, no.7, pp.812-814, 1993.

[40] S. Takahashi, "Prospects for ultra-low loss using fluoride glass optical fiber: A review," J. Non-Cryst. Solids, vol.140, pp.172-178, 1992

[41] T. Kanamori and S. Sakaguchi, "Preparation of elevated NA fluoride optical fibers," Jpn. J. Appl. Phys., vol.25, no.6, pp.L468-L470, 1986.

[42] S.F. Carter, M.W. Moore, D. Szebesta, J.R. Williams, D. Ranson, and P.W. France, "Low loss fluoride fibre by reduced pressure casting," Electron. Lett., vol.26, no.25, pp.2115-2117, 1990.

[43] D. Szebesta, S.T. Davey, J.R. Williams, and M.W. Moore, "OH absorption in the low loss window of ZBLAN(P) glass fibre," Proc. Eighth Inter. Symp. on halide glasses, pp.18-22, Sept. 1992.

[44] Y. Ohishi, T. Kanamori, T. Kitagawa, and S. Takahashi, " $\mathrm{Pr}^{3+}$-doped fluoride fiber amplifier operating at $1.31 \mu \mathrm{m}$," Opt. Lett., vol.16, no.22, pp.1747-1749, 1991.

[45] S. Sakaguchi, S. Todoroki, and T. Murata, "Rayleigh scattering in silica glass with heat treatment," J. Non-Cryst. Solids, vol.220, no.23, pp.178-186, 1997.

[46] A.E. Geissberger and F.L. Galeener, "Raman studies of vitreous $\mathrm{SiO}_{2}$ versus fictive temperature," Phys. Rev. B, vol.28, no.6, pp.3266-3271, 1983.

[47] N. Shimodaira, K. Saito, and A.J. Ikushima, "Raman spectra of fluorine-doped silica glasses with various fictive temperatures," J. Appl. Phys., vol.91, no.6, pp.3522-3525, 2002.

[48] H. Kakiuchida, K. Saito, and A.J. Ikushima, "Precise determination of fictive temperature of silica glass by infrared absorption spectrum," J. Appl. Phys., vol.93, no.1, pp.777-779, 2003.

[49] S. Todoroki and S. Sakaguchi, "Rayleigh scattering and fictive temperature in VAD silica glass with heat treatment," J. Ceram. Soc. Jpn., vol.105, no.5, pp.377-380, 1997.

[50] F.L. Galeener, "Planar rings in vitreous silica," J. Non-Cryst. Solids, vol.49, no.1-3, pp.53-62, 1982.

[51] H.N. Daglish, "Light scattering in selected optical glasses," Glass Tech., vol.11, no.2, pp.30-35, 1970.

[52] J. Schroeder, R. Mohr, C.J. Montrose, and P.B. Macedo, "Light scattering in a number of optical grade glasses," J. Non-Cryst. Solids, vol.13, no.2, pp.313-320, 1973.

[53] K. Saito, H. Kakiuchida, and A.J. Ikushima, "Light-scattering study of the glass transition in silica, with practical implications," J. Appl. Phys., vol.84, no.6, pp.3107-3112, 1998.

[54] H. Hattori, Y. Ohishi, T. Kanamori, and S. Takahashi, "Scattering loss measurement for small segments of fluoride optical fibers," Appl. Opt., vol.25, no.19, pp.3549-3551, 1986.

[55] I.V. Pevnitskii and V. Kh. Khalilov, "Light scattering in vitreous silica," Soviet J. Glass Phys. Chem., vol.15, pp.246-250, 1989.

[56] S. Sakaguchi and S. Todoroki, "Rayleigh scattering of silica glass and silica fibers with heat treatment," Jpn. J. Appl. Phys., vol.37, no.S1, pp.56-58, 1998 .

[57] K. Tajima, M. Ohashi, K. Shiraki, M. Tateda, and S. Shibata, "Low Rayleigh scattering $\mathrm{P}_{2} \mathrm{O}_{5}-\mathrm{F}-\mathrm{SiO}_{2}$ glasses," J. Lightwave Technol., vol.10, no.11, pp.1532-1535, 1992.

[58] K. Tajima, M. Tateda, and M. Ohashi, "Low Rayleigh-scattering loss of $\mathrm{P}_{2} \mathrm{O}_{5}-\mathrm{SiO}_{2}$-core single-mode fiber," Tech. Dig. Conf. on Opt. Fiber Comm. OFC'94, TuB2, Feb. 1994.

[59] M.E. Lines, "Can the minimum attenuation of fused silica be significantly reduced by small compositional variations? I. Alkali metal dopants," J. Non-Cryst. Solids, vol.171, no.3, pp.209-218, 1994.

[60] K. Saito, A.J. Ikushima, T. Ito, and A. Itoh, "A new method of developing ultralow-loss glasses,” J. Appl. Phys., vol.81, no.11, pp.71297134, 1997.

[61] M. Ogai, A. Iino, K. Matsubara, J. Tamura, M. Koguchi, S.
Nakamura, and E. Kinoshita, "Development and performance of fully fluorine-doped single-mode fibers," J. Lightwave Technol., vol.6, no.10, pp.1455-1461, 1988.

[62] M.E. Lines, "Can the minimum attenuation of fused silica be significantly reduced by small compositional variations? II. Combined fluorine and alkali metal dopants," J. Non-Cryst. Solids, vol.171, no.3, pp.219-227, 1994.

[63] K. Saito and A.J. Ikushima, "Effects of fluorine on structure, structural relaxation, and absorption edge in silica glass," J. Appl. Phys., vol.91, no.8, pp.4886-4890, 2002.

[64] H. Kakiuchida, H. Saito, and A.J. Ikushima, "Rayleigh scattering in fluorine-doped silica glass," Jpn. J. Appl. Phys., vol.42, no.10, pp.6516-6517, 2003.

[65] K. Saito and A.J. Ikushima, "Structural relaxation enhanced by Cl ions in silica glass," Appl. Phys. Lett., vol.73, no.9, pp.1209-1211, 1998

[66] K. Tajima, "Low-loss optical fibers realized by reduction of Rayleigh scattering loss,” Tech. Dig. Conf. on Opt. FiberComm'98, ThK5, Feb. 1998

[67] K. Tsujikawa, K. Tajima, and M. Ohashi, "Rayleigh scattering reduction method for silica-based optical fiber," J. Lightwave Technol., vol.18, no.11, pp.1528-1532, 2000.

[68] K. Saito, M. Yamaguchi, H. Kakiuchida, and A.J. Ikushima, "Limit of the Rayleigh scattering loss in silica fiber," Appl. Phys. Lett., vol.83, no.25, pp.5175-5177, 2003.

[69] K. Nagayama, M. Kakui, M. Matsui, T. Saitoh, and Y. Chigusa, "Ultra-low-loss $(0.1484 \mathrm{~dB} / \mathrm{km})$ pure silica core fibre and extension of transmission distance," Electron. Lett., vol.38, no.20, pp.11681169,2002

[70] S. Ohnuki, K. Kuwahara, K. Morita, and Y. Koyano, "Further attenuation improvement of a pure silica core fiber with large effective area," Proc. SubOptic 2010, Paper THU3A, May 2010.

[71] M. Hirano, T. Haruna, Y. Tamura, T. Kawano, S. Ohnuki, Y Yamamoto, Y. Koyano, and T. Sasaki, "Record low loss, record high FOM optical fiber with manufacturable process," Proc. Opt. Fiber Comm. Conf. 2013, Paper PDP5A.7, March 2013.

[72] S. Makovejs, C.C. Roberts, F. Palacios, H.B. Matthews, D.A. Lewis, D.T. Smith, P.G. Diehl, J.J. Johnson, J.D. Patterson, C.R. Towery, and S.Y. Ten, "Record-low $(0.1460 \mathrm{~dB} / \mathrm{km})$ attenuation ultra-large $\mathrm{A}_{\mathrm{eff}}$ optical fiber for submarine applications," Proc. Opt. Fiber Comm. Conf. 2015, Paper Th5A.2, March 2015.

[73] Y. Tamura, H. Sakuma, K. Morita, M. Suzuki, Y. Yamamoto, K. Shimada, Y. Honma, K. Sohma, T. Fujii, and T. Hasegawa, "Lowestever 0.1419-dB/km loss optical fiber," Proc. Opt. Fiber Comm. Conf. 2017, Paper Th5D.1, March 2017.

[74] H. Yamaguchi, Y. Yamamoto, T, Hasegawa, T. Kawano, M. Hirono, and Y. Koyano, "Ultra-low loss and large Aeff pure-silica-core fiber advances," Proc. SubOptic 2016, Paper EC07, April 2016.

[75] Y. Tamura, H. Sakuma, K. Morita, M. Suzuki, Y. Yamamoto, K. Shimada, Y. Honma, K. Sohma, T. Fujii, and T. Hasegawa, "The first $0.14-\mathrm{dB} / \mathrm{km}$ loss optical fiber and its impact on submarine transmission," J. Lightwave Technol., vol.36, no.1, pp.44-49, 2018.

[76] F. Palacios, R. Lemaitre, P. Debeusscher, and C. Bibelrhach, "Ultralarge effective area fibre performances in high fibre count cables and joints, a new technical challenge," Proc. SubOptic 2016, Paper EC06, April 2016.

[77] Y. Yamamoto, M. Hirano, K. Kuwahara, and T. Sasaki, "OSNRenhancing pure-silica-core fiber with large effective area and low attenuation,” Proc. Opt. Fiber Comm. Conf. 2010, Paper OTuI2, March 2010.

[78] Y. Yamamoto, Y. Kawaguchi, and M. Hirano, "Low-loss and lownonlinearity pure-silica-core fiber for $\mathrm{C}$ - and L-band broadband transmission," J. Lightwave Technol., vol.34, no.2, pp.321-326, 2016

[79] T. Hayashi, Y. Tamura, T. Hasegawa, and T. Taru, "Record-low spatial mode dispersion and ultra-low loss coupled multi-core fiber for ultra-long-haul transmission,” J. Lightwave Technol., vol.35, no.3, 
pp.450-457, 2017.

[80] Y. Tamura, T. Hayashi, T. Nakanishi, and T. Hasegawa, "Low-loss uncoupled two-core fiber for power efficient practical submarine transmission," Proc. Opt. Fiber Comm. Conf. 2019, Paper M1E.5, March 2019.

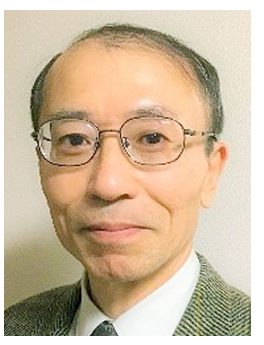

Hiroo Kanamori received the B.S. and M.S degrees in Physics from Tokyo Institute of Technology in 1979 and 1981, respectively. In 1981, he joined Sumitomo Electric Industries, Ltd. and has been engaged in the R\&D and manufacturing of optical fibers, optical passive components, and optical modules. He is a member of IEICE. He received Shinohara Memorial Young Investigators Award in 1986. 